EESTI NSV TEADUSTE AKADEEMIA TOIMETISED. XV KÖIDE FUUSIKA-MATEMAATIKA-JA TEHNIKATEADUSTE SEERIA. 1966, NR. 2

ИЗВЕСТИЯ АКАДЕМИИ НАУК ЭСТОНСКОЙ ССР. ТОМ ХV СЕРИЯ ФИЗИКО-МАТЕМАТИЧЕСКИХ И ТЕХНИЧЕСКИХ НАУҚ. 1966, № 2

Х. АНДРА, Ю. ХЕИНСАЛУ

\title{
ДРЕВНЯЯ ДОЛИНА И КАРСТ ПО ЗОНЕ ТРЕЩИНОВАТОСТИ СЕВЕРО-ЗАПАДНОГО ПРОСТИРАНИЯ В ОКРЕСТНОСТЯХ ПОРКУНИ (СЕВЕРНАЯ ЭСТОНИЯ)
}

Коренными породами североэстонского плато, покрытого маломощными четвертичными отложениями, являются карбонатные породы ордовика и силура. В последних наблюдается густая сеть тектонических трещин, имеющих северо-западное, северовосточное, широтное и меридиональное простирание [3]. Среди этих трещин преобладающими являются трещины северо-западного простирания. Многие реки, протекающие по названному плато и впадающие в Финский залив, имеют северо-западное или близ кое к меридиональному направление. Эти реки текут по частично погребенным долинам и ложбинам. Древние долины местами хорошо выражены в современном рельефе, но иногда они полностью погребены под четвертичными отложениями и незаметны.

Указанное направление рек совпадает с простиранием большинства тектонических түещин, на что давно обратили внимание некоторые исследователи [1-3].

Одной из наиболее крупных древних долин северо-западного направления, хорошо выраженной в современном рельефе, является долина Поркуни [ $\left.{ }^{4}\right]$, расположенная на северо-западном склоне возвышенности Пандивере - самой высокой восточной части североэстонского водораздела с относительной высотой 40-50 м. По этой долине течет река Вальгейыги, берущая свое начало в озере Поркуни, расположенном в юго-восточном конце долины северо-западного простирания. В юговосточном направлении долина прослеживается далее только в виде ложбины. Озеро питается в основном подводными карстовыми источниками. К юго-востоку от него в современном рельефе наблюдается только пологая ложбина, прослеживающаяся до деревни Коону на протяжении $1,5 \kappa \mu$.

В современном рельефе возвышенности Пандивере долина Поркуни выражена резко. Она имеет вид прямолинейной $U$-образной долины шириной до 400 и глубиной до 15 м. Длина долины составляет около $16 \kappa м$. Склоны ее весьма крутые.

За пределами возвышенности Пандивере река Вальгейыги течет по североэстонскому плато в северо-западном направлении еще около $18 \kappa м$. Местами она протекает здесь по заболоченным низинам, и долина ее выражена слабо. Только около глинта долина имеет каньонообразную форму. Ниже глинта река Вальгейыги течет в северном направлении.

В ходе изучения распространения карста на возвышенности Пандивере выяснилось, что на юго-восточном продолжении древней долины Поркуни имеется ряд карстовых полей, а также отдельных карстовых воронок (рис. 1), описание которых следует ниже. На карстовом поле Везиору площадью 3 га расположены четыре ваннообразные коррози- 


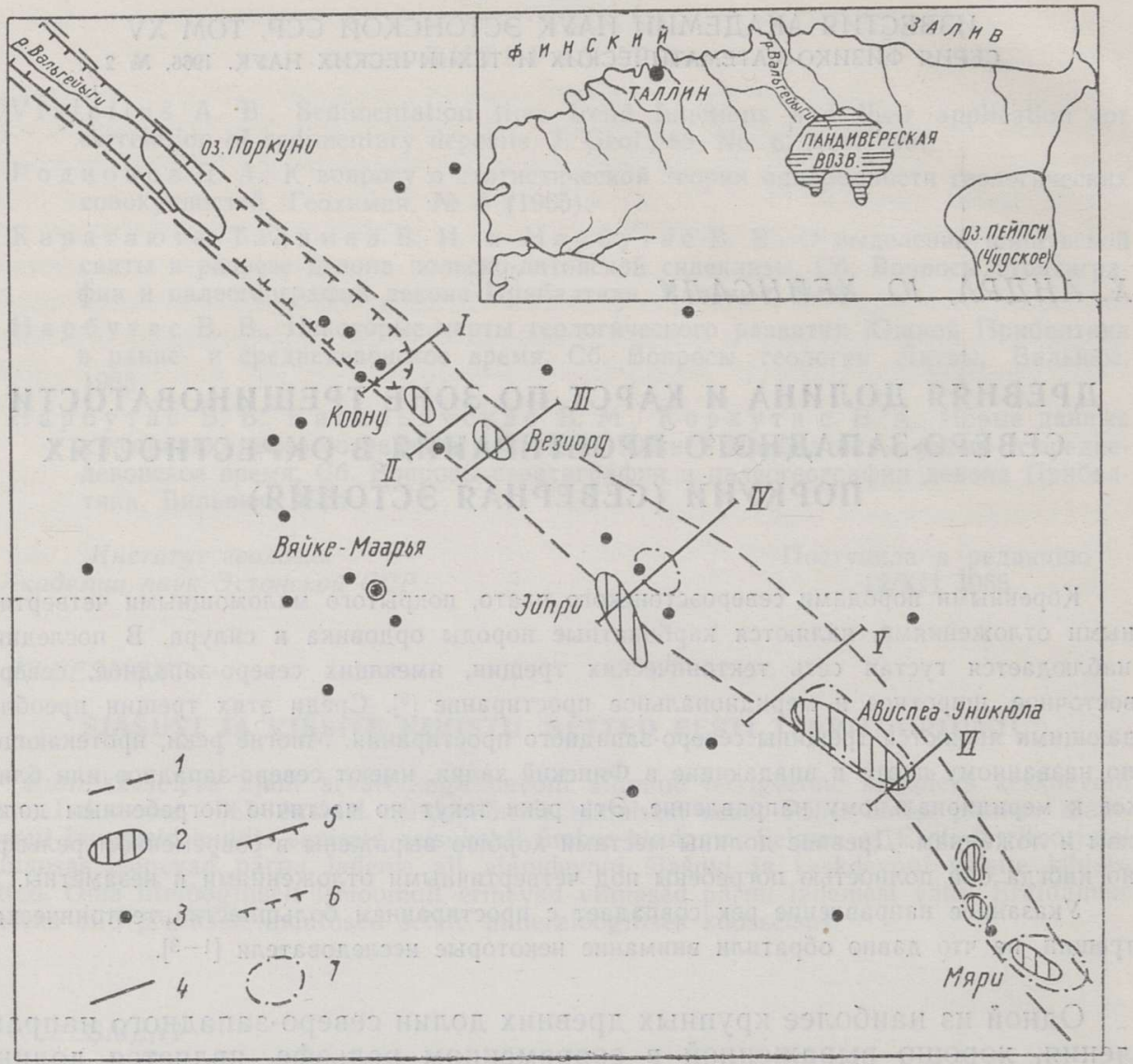

Рис. 1. Схематическая карта рек Северной Эстонии (врезка) и расположение зоны трещиноватости на продолжении реки Вальгейыги: 1 - граница зоны трещиноватости, выявленная электропрофилированием; 2 - карстовые поля; 3 отдельные карстовые воронки; 4 - трассы электропрофилей; 5 - древняя долина Поркуни; 6 - ложбина в современном рельефе; 7 - погребенные карстоводенудационные впадины. Римскими цифрами обозначены места расположения электропрофилей.

онно-суффозионные воронки с азимутом длинной оси $290-315^{\circ}$. Три из них располагаются цепочкой. Длина этих воронок достигает 80 , ширина -25 и глубина $-2-3$ м. Кроме того, на карстовом участке имеется еще шесть заиленных карстовых воронок диаметром до 10 и глубиной 1 м. На карстовом поле Эйпри площадью 3 га, расположенном в центральной части долины, находится около 15 коррозионно-суффозионных воронок. Қарстовые формы здесь обычно конусообразные и имеют в плане круглую или неправильную вытянутую форму. Имеются и цепочки из 3-5 воронок длиной до 50 , которые вытянуты в северо-западном или меридиональном направлении. Диаметр воронок достигает 15 и глубина -4 м. Продолговатые воронки имеют обычно азимут $310-345^{\circ}$. Карстовое поле в деревне Ависпеа-Уникюла имеет ширину 700 и длину около 1700 м. Более крупными карстовыми формами являются здесь семь коррозионно-суффозионных долин длиной до 200, шириной до 60 и глубиной до 3 м. Карстовые долины вытянуты в северо-западном направлении (азимут $300-320^{\circ}$ ) и располагаются местами двумя-тремя параллельными цепочками. Кроме того, на этом поле встречаются еще 
многочисленные карстовые воронки диаметром $10-40$ и глубиной $1-2$ м. Те из них, которые имеют овальную форму, также вытянуты в северо-западном направлении.

Отдельные карстовые воронки на юго-восточном продолжении долины Поркуни встречаются в виде курису (местное название поглощающих карстовых воронок), а также в виде мелких провальных воронок. По форме и величине карстовые воронки здесь не отличаются от воронок, находящихся в других районах Пандивереской возвышенности, но имеют обычно вытянутую в северо-западном направлении форму (азимут 300$\left.330^{\circ}\right)$. Длина воронок достигает 40 , ширина - 10-20 и глубина - 3,5 . Они врезаются в коренные породы не более чем на 0,5 м. Поноры на дне курису обычно покрыты маломощным слоем промытой морены. Вода, стекающая весной в воронки, фильтруется через эти отложения или поглощается прямо через мелкие ходы, развитые в отложениях. Курису могут поглощать до $5-20 \Omega$ воды в секунду, а иногда и больше.

Провальные воронки встречаются, как правило, в незначительных чожбинах рельефа с мощностью четвертичных отложений не более $3-4 м$. Их размеры в поперечнике не превышают $2-4$ и глубина - также $2-4 м$ (обычно их ширина 2 и глубина $1,5 \mu$ ). Образуются они в течение нескольких лет, в разных местах, в четвертичных отложениях после весеннего снеготаяния, когда ложбины заполняются водой. Вода, проникая через четвертичный покров в древние карстовые поноры и трещины, вызывает интенсивное развитие карстово-суффозионных процесссв. Провальные воронки, образующиеся на полях, заполняются обычно валунами и землей.

Распространение и характер современного карста в юго-восточном продолжении долины Поркуни свидетельствуют о хорошо развитой трещиноватости коренных пород. Это навело нас на мысль о существованіии зоны трещиноватости северо-западного простирания по древней долине Поркуни и юго-восточнее ее. Для исследования вопроса над предполагаемой зоной трещиноватости было проведено вертикальное электрическое зондирование и электропрофилирование. Результаты зондирования показали, что геоэлектрический раззез в пределах зоны существенно отличается от нормального разреза, полученного за ее пределами (рис. 2). Верхняя часть нормального геоэлектрического разреза на выходе тамсалуского горизонта (рис. 2 , 2), на котором находится исследованная зона, соответствует переходу от четвертичных отложений к известнякам тамсалуского горизонта. Нижняя часть этой кривой характери-

Рис. 2. Кривые вертикального зондирования (ВЭЗ) около дер. Коону: 1 - кривая, характеризующая зону трещиноватости; 2 - кривая, характеризующая ненарушенные коренные породы.

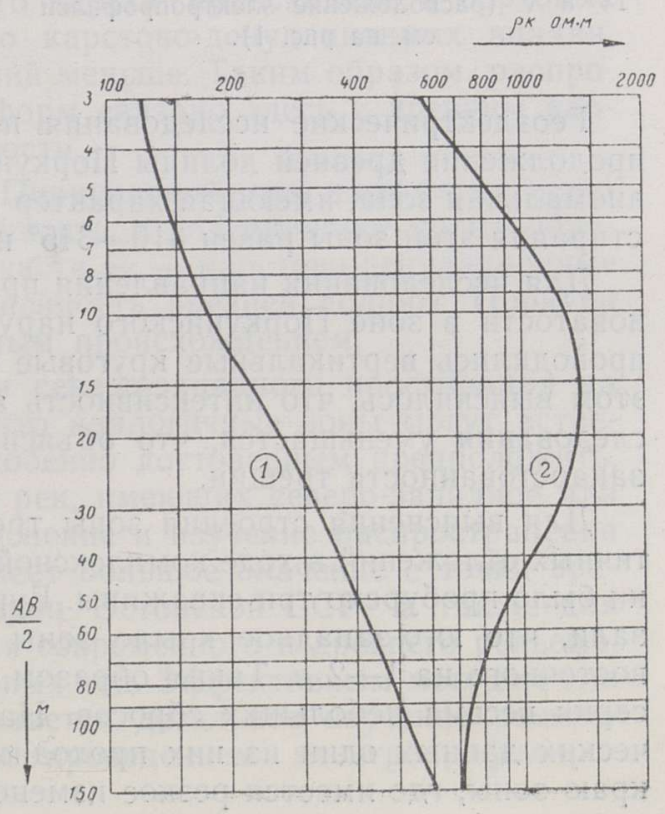


зует мергелистый юуруский горизонт, залегающий под тамсалуским горизонтом. Максимум $\varrho_{k}$ в средней части разреза обусловлен высоким сопротивлением пород тамсалуского горизонта. У кривых зондирования, полученных в пределах исследованной зоны (рис. 2,1 ), отсутствует максимум в средней части кривой (при разносах $\frac{A B}{2}=15 \div 20 \mu$ ), при этом разница в сопротивлениях достигает более 1000 ом

Большие разности в сопротивлениях и значительная ширина исследованной зоны позволили применить при проведении электропрофилирования самую простую и экономичную однократную симметричную установку при схеме $A M N B$ с $A B=40$ м $M N=10$ м с шагом $10-100$ м. Эффективный разнос $A B$ был определен путем сравнения кривых электрического зондирования, снятых на нормальных и нарушенных участках пород. Электропрофилирование проводилось на шести профилях с

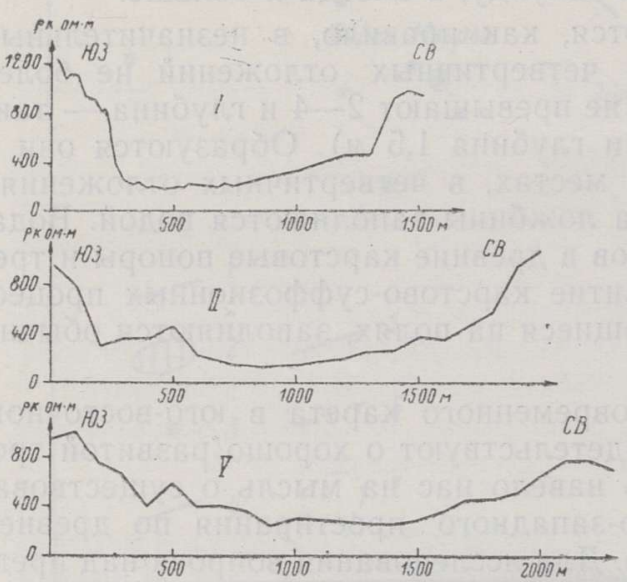

Рис. 3. Кривые электропрофилирования 1, IV и V (расположение электропрофилей см. на рис. 1).

расстоянием между профилями до 1,5 км вкрест простирания зоны (азимуты 45-50). Полученные кривые характеризуются большим изменением удельного кажущегося сопротивления, значение которого в центральной части аномальной зоны достигает $200-300$ ом $\boldsymbol{M}$, а за его пределами 1200 1650 ом $\mathcal{M}$ (рис. 3). Характерной чертой исследованной аномалии являются большие изменения кажущегося удельного сопротивления в его краевых частях. Особенно резкое изменение сопротивления имеет место на некоторых профилях в юго-западной стороне зоны, достигающее 1450 ом $\boldsymbol{M}$ на 100-метровом участке на профиле II.

Геоэлектрические исследования показывают, что на юго-восточном продолжении древней долины Поркуни существует хорошо выраженная аномальная зона, имеющая характер зоны трещиноватости. Азимут простирания этой зоны равен $310-345^{\circ}$ и ширина - от 0,6 до 1,8 км.

Для исследования направления простирания и интенсивности трещиноватости в зоне Поркуниского нарушения в зависимости от глубины проводились вертикальные круговые электрические зондирования. При этом выяснилось, что интенсивность анизотропии с ростом глубины исследования уменьшается, что объясняется, по-видимому, уменьшением закарстованности трещин.

Для выяснения строения зоны трещиноватости и мощности четвертичных отложений в ходе комплексной геолого-гидрогеологической съемки было пробурено три скважины. Буровые скважины (рис. 4, III) показали, что юго-западное крыло зоны приподнято в отношении северовосточного на $1-2$ м. Таким образом, по зоне предполагается сброс или серия весьма небольших сбросов. На основе геологических и геофизических данных один из них проходит, по-видимому, по юго-западному краю зоны, где имеется резкое изменение кажущегося удельного сопро- 
тивления (рис. 4). Весьма примечательно, что именно к этому краю зоны приурочено большинство карстовых явлений. Данные бурения показывают еще, что в центральной части зоны нарушения известняки доломи-

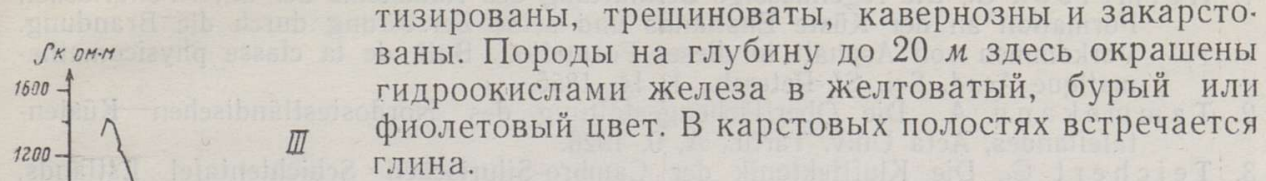

Геологическими и геофизическими исследованиями установлено еще, что в

Рис. 4. Геологический разрез зоны трещиноватости около дер. Везиору и соответствуішая кривая электропрофилирования III: 1 -морена; 2 - песчано-гравийные отложения; 3 - глина; 4 - известняки; 5 трещиноватость.

промежутке между озером Поркуни и деревней Эйпри над зоной нарушения имеется погребенная долина, которая является продолжением древней долины Поркуни. Мощность четвертичных отложений здесь в широкой полосе значительная, достигая, по данным шахтных и буровых колодцев, 18 м. Большие мощности четвертичных отложений встречаются над зоной еще и юго-восточнее деревни Эйпри (например, в Ависпеа - 12 м, в Мяри - 9 м). Значительные мощности четвертичных отложений связаны здесь, по-видимому, с наличием погребенных карстово-денудационных впадин, которые вытянуты в северо-западном направлении. Развитие современного карста происходило в бортовых частях погребенных долин и около карстово-денудационных впадин, где мощность четвертичных отложений меньше. Таким образом, распространение современных карстовых форм связано здесь с древним карстом, развитым по зоне трещиноватости.

Из сказанного следует, что вдоль Поркуниской зоны нарушения, пересекающего Пандиверескую возвышенность, в доледниковое время образовалась долина, а в юго-восточной части ее - карстово-денудационные впадины. Таким образом, прямолинейность древней долины Поркуни объясняется ее структурно-эрозионным происхождением.

Выявление зоны трещиноватости северо-западного простирания на североэстонском плато указывает, что аналогичные зоны могут встрєчаться здесь и в других местах. Особенно достоверным предположить, что они находятся на местах долин рек, имеющих северо-западное или северное направления. Поэтому выяснение и изучение распространения и характера зон трещиноватости имеет большое значение с точки зрения структурного строения территории Эстонской ССР, а также для выяснения закономерностей развития современного и древнего рельефа, карста и движения трещинно-карстовых вод. Эффективным методом для выявления и изучения этих зон является детальное изучение распространения карста с параллельным проведением электропрофилирования. 


\section{ЛИТЕРА Т У Р А}

1. Hel me rs en G., Die regelmässige Zerklüftung des Kalksteins der untern-silurischen Formation an der Küste Ehstlands und seine Zerstörung durch die Brandung. Vorkommen von Asphalt in dieser Formation, Bull. de la classe physicomathematique Acad. Sci. St.-Petersb., 1, 14, 1856.

2. T a mmekann A., Die Oberflächengestaltung des Nordostestländischen Küstentafellandes, Acta Univ. Tartu., A, 9, 1926.

3. Te ichert C., Die Klufttektonik der Cambro-Silurischen. Schichtentafel Estlands, Geol. Rundschau, Bd. XVIII, H. 4, 1927.

4. Ö pik A., Porkuni-Tamsalu ümbruse geoloogiast, Eesti Loodus, nr. 2, 1937.

Ннститут геологии

Академии наук Әстонской ССР
Поступила в редакцию $4 / \mathrm{V} \quad 1965$

\section{H. ANDRA, U. HEINSALU}

\section{URGORG JA KARST LOODE-KAGU-SUUNALISES LOHELISUSVÖONDIS PORKUNI OMBRUSES POOHJA-EESTIS}

Karstiväljade ja karstilehtrite leviku pilt ja elektromeetrilised uurimised näitavad, et Porkuni ürgoru kagusuunalisel pikendusel esineb lőhelisüsvöönd, mis läbib Pandivere kõrgustikku. Vööndis esineb murrang või seeria murranguid, mille summaarne amplituud on 1-2 m. Lõhelisusvööndi kohal on ürgorg ja karsti-denudatsioonilised nõod mattunud: Seega on loode-kagu-suunaline Porkuni ürgorg struktuurilt erosioonilise tekkega.

Loode-kagu-suunalise lõhelisusvööndi ilmsikstulek Põhja-Eesti lavamaal osutab, et sellesuunalisi vööndeid võib esineda mujalgi, eriti loode-kagu- ja põhja-lõuna-suunaliste jõeorgude kohal. Nende uurimisel on ériti efektiivne sümmeetriline elektroprofileerimine ning detailne karstinähtusste kaardistamine.

\section{H. ANDRA, U. HEINSALU}

\section{ANCIENT VALLEY AND KARST IN THE NW-SE-DIRECTED SHEAR ZONE IN THE ENVIRONMENT OF PORKUNI IN NORTHERN ESTONIA}

The map of the distribution of karst fields and craters as well as electromagnelic investigations show that at an elongation of the ancient valley of Porkuni in a southeasterly direction there occurs a shear zone which intersects the elevation of Pandivere There is a fault or series of faults in the zone, with a summary amplitude of $1-2$ metres...In the shear zone we find a buried ancient valley and some karst-denudational depressions. Thus the NW-SE-directed ancient valley of Porkuni is of a structuralerosional origin.

The appearance of a-NW-SE-directed shear zone on the North-Estonian plateau shows that similar zones may occur in other places as well, and in particular in the river-valleys of a NE-SW and N-S direction. For a study of these zones, the method of symmetric electroprofiling and a detailed mapping of karst phenomena have proved to be particularly effective. 